\title{
USING PASSIVE MICROWAVE REMOTE SENSING TECHNIQUES IN MAPPING SOIL MOISTURE ON A REGIONAL SCALE
}

\section{INTRODUCTION}

Recent landscape ecology investigations have increasingly involved remote sensing techniques (Quattrochi and Pelletier, 1991; Frohn, 1998). These techniques can be used to register and map resources, quantify environmental characteristics, and evaluate changes in ecosystem management.

Since remotely sensed data can be collected at multiple times and at multiple scales, it can be used at different scales for landscape analysis. Frequent and repetitive remote sensing imagery enables monitoring and prediction of environmental phenomena. Each environmental component has its own characteristic multispectral response. The most commonly use portion of the electromagnetic spectrum is the reflective portion, mainly used for land cover/ land use and landform characteristics (Johnston, 1998). Land cover classifications are often used next in landscape pattern and structure analysis (Frohn, 1998).

However, longer wavelengths in the microwave part of the spectrum, offer additional possibilities in landscape investigations. Active microwave or radar methods can be used to determine landscape microtopography (Wu, 1984) as well as vegetation canopy density and structure analysis. Both active and passive microwave methods can be a powerful tool in analyzing soil moisture distribution (Du et al., 2000; Jackson et al., 1996) - an important part of processes taking place in landscapes.

Water plays an important role in the matter exchange. Its constant circulation is an essential element in multi-interactions with other landscape components (Falkenmark and Mikulski, 1994). The rate of infiltration is determined primarily by soil texture and the degree of saturation. Knowledge of the current soil moisture condition is crucial in predicting infiltration and surface runoff.

Relief and texture are stable within the landscape and usually well known. However, soil moisture, is a very dynamic environmental element, changes rapidly over space and time and is hard to assess. Its mapping by conventional methods requires ground samplings measurements that are time, labor and 
cost consuming. This task is especially difficult when daily series data are needed. One solution for this is a remote sensing techniques combined with Geographical Information Systems (GIS), which offer a quick and reliable way of soil moisture mapping (i.e. Oldak and Jackson, 1999).

This paper presents how remote sensing techniques can be implemented in acquiring soil moisture on regional scale. The basis of this are the results of a large-scale aircraft experiment.

\section{MICROWAVE REMOTE SENSING IN SOIL MOISTURE MAPPING}

Recent advances in remote sensing provide a growing database for understanding patterns of water content and rates of water transport in soils and landscapes. Active and passive microwave methods are currently used intensively. Active methods employ radars to send microwave pulses that are then reflected, and the received signals are recorded. Passive methods rely on measuring natural emission from the land surface at microwave wavelengths. Soil water content affects the microwave measurements in both methods, so that changes in soil moisture in time and space can be registered. Microwave techniques are capable of measuring the surface soil moisture up to the depth of $5 \mathrm{~cm}$ (Jackson, 1993). At wavelengths used in soil moisture studies, microwave measurements are not sensitive to weather conditions and can detect soil moisture through cloud cover. Vegetation is semi-transparent for microwaves, making it possible to observe the underlying surface. Solar illumination is not necessary, and the observations can be made around the clock. Topography of the area can affect the brightness temperature measurements (based on the viewing angle of the radiometer) only when slopes are greater then $10^{\circ}$ (Jackson, 1993). Active microwave instruments generally offer relatively high spatial resolution, up to $20 \mathrm{~m}$ even from spacecraft altitudes. However, backscattered radar signals are often difficult to interpret in terms of soil moisture content because of variability in other environmental factors such as surface roughness. Passive microwave systems on satellite platforms have low resolution up to $50 \mathrm{~km}$, but deploying them on aircrafts typically yields resolutions between 100 and $1000 \mathrm{~m}$. Airborne passive measurements were successfully implemented in recent soil moisture studies on a regional scale (Jackson et al., 1995; 1999).

One instrument in current use is the Electronically Scanned Thinned Array Radiometer (ESTAR) (Jackson et al., 1995). This passive microwave radiometer operates at center frequency of $1.415 \mathrm{GHz}(\mathrm{L}$ band, $21 \mathrm{~cm}$ ) and measures brightness temperature of the object. Brightness temperature (TB) is microwave energy radiated from the surface and depends on the product of its physical temperature (T) and emissivity (e).

Emissivity can be related to the dielectric constant of the soil defined as a composite of three basic elements - solid particles, air and water. Each element has different dielectric constant in time and space, depending on the water content. The higher the water content in the soil - the higher 
the dielectric constant (which for water is about 80 and for dry soil is about 5) and the lower the value of emissivity and brightness temperature measured by the radiometer.

The algorithm for volumetric soil moisture retrieval, from passive microwave measurements, requires several additional environmental varieties (Jackson, 1993), what is discussed in more detail in the later sections of the paper. All the spatial data have to be combined together in order to perform algorithm calculations; GIS is ideally suited for this purpose (Oldak and Jackson, 1999).

\section{FIELD EXPERIMENT}

As an example of the potential of microwave remote sensing of soil moisture, data collected in the 1997 Southern Great Plains Hydrology Experiment (SGP97) will be examined. One of the objectives of this project was to map soil moisture on a daily basis during four weeks, since $18^{\text {th }}$ June through $16^{\text {th }}$ July (full documentation for the experiment can be found on the website address: http://hydrolab.arsusda.gov/sgp97/ and Jackson et al., 1999).

The study area, as shown in Figure 1, lies predominantly within the Central Rolling Red Prairies and Central Rolling Red Plains mostly within the state of Oklahoma (Gray and Galloway 1969). The slopes calculated from 100-m resolution Digital Elevation Model within the flight area being analyzed in this work (shown on Fig. 1) vary from 0 to $2.3 \%$, but most fall in 0.5 to $1.1 \%$. The total area under study was about $10,000 \mathrm{~km}^{2}$.

Annual rainfall ranges from $875 \mathrm{~mm}$ in the east (Red Prairies) to about $711 \mathrm{~mm}$ in the west (Red Plains). Among soil texture categories silt loam was the dominant soil texture (59.7\%), followed by loam (16.8\%) and sandy loam (14.5\%). Soils in the region are predominantly Mollisols (grassland soils) having low leaching (low precipitation - subhumid to semiarid climate) with relatively large annual additions of organic matter. Pasture and forage were the dominant land cover categories (48.4\%) in the research area, followed by wheat $(21.8 \%)$, urban area $(7.1 \%)$, alfalfa $(5.5 \%)$, shrubs $(4.8 \%)$, trees $(3.3 \%)$, and corn (3.2\%). Other categories include bare soils, legume, summer corn and summer legume, which altogether with the unclassified areas take 5.9\% of the area in question.

\section{GIS FOR SOIL MOISTURE ALGORITHM}

\section{Input Data Layers}

Soil moisture retrieval algorithm combines data layers coming from different sources (Fig. 2). There were aircraft and satellite data, thematic maps and point measurements.

The core layer for the model data input was the brightness temperature data. It was measured with the Electronically Scanned Thinned Array Radiometer 
(ESTAR) deployed on the NASA-P3 aircraft. The observation area was 40-km wide east west and $250-\mathrm{km}$ long north south (Fig. 1). ESTAR produces a spatially distributed map product. The resulting pixel size from the ESTAR image depends on latitude, changing from $554.6 \mathrm{~m}$ in the $x$ direction and $461.9 \mathrm{~m}$ in the $y$ direction at 34 degree of latitude to $555.0 \mathrm{~m}$ and $436.2 \mathrm{~m}$ respectively at 38.5 degree. The uniform GIS database required re-gridding of original irregular resolution. The original brightness temperature data were interpolated into regular 800-m grid using mapping software. This grid size in UTM (Zone $14 \mathrm{~S}$ ) coordinate system was established as the basic resolution for the GIS layers in the soil moisture retrieval

Essential data layers for the model were derived from land cover categories. The presence of vegetation cover reduces microwave sensitivity to soil moisture variations. Two features are important for assessing the influence of vegetation canopies on microwave signal: vegetation water content and canopy structure, described by vegetation parameter as shown on Figure 2 (Jackson and Schmugge, 1991). These two parameters determine the optical depth of the canopy, which is in turn responsible for vegetation layer transmissivity, attenuating the microwave signal from the soil surface. The bigger the optical depth the greater is the attenuating effect on microwave signal.

Another feature of surface - its roughness - effects the emission signal. Increasing roughness results in an increase in the emissivity over that of a smooth surface. Surface roughness, vegetation water content and canopy parameter are associated with land cover types. This is why land cover is a critical data layer in the GIS database.

Land cover categories were developed from several Landsat TM images, acquired during the time of the SGP97 experiment as described by Doraiswamy et al. (1998). These original land cover categories were important for screening for specific classes (grass categories, stalk-dominated vegetation, bare lands, shrubs, and others) in order to evaluate the influence of surface roughness and vegetation cover on soil emissivity. Using the land cover classes, fixed values from the attribute tables, as presented in Jackson et al. (1999), were assigned to obtain a spatial distribution of the canopy parameter, surface roughness, vegetation water content and soil bulk density under different land cover categories.

In determining the vegetation water content special attention was paid to the grass categories, which were the dominant land cover types in the research area. For these categories, water content was estimated based on field measurements. The field measurements, conducted during the experiment period, within the test areas as shown on Fig. 1, were compared with Normalized Difference Vegetation Index values. NDVI was calculated from the July $25^{\text {th }}$, Landsat TM image. A second order polynomial function was used to establish a relationship between NDVI and vegetation water content (Jackson et al., 1999). With this function embedded into the GIS model, the spatial distribution of vegetation water content was calculated for the grass areas. 


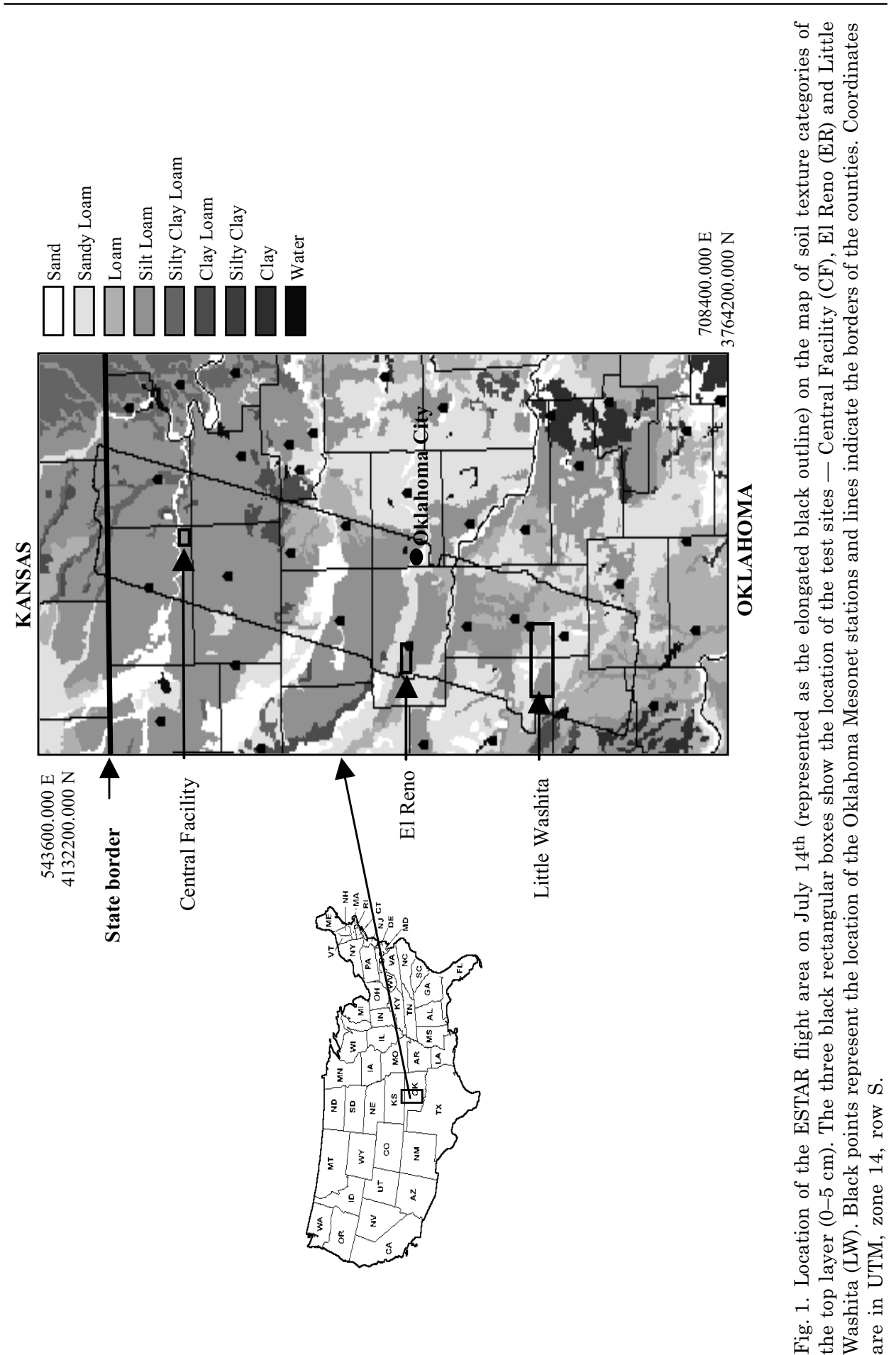


All four data layers derived from land cover classification, gridded as $30-\mathrm{m}$ cells, were averaged in $27 \times 27$ blocks of pixels and georegistered to $800-\mathrm{m}$ resolution to match the established GIS database.

Another data layer important for model calculation was soil texture data. Soil texture data layers over the SGP97 area were developed using a version of the STATSGO ${ }^{1}$ soil database in $1-\mathrm{km}$ grid. The data set was provided by Penn State's Earth System Science Center (Miller, 1997). The layer of the depth $0-5 \mathrm{~cm}$ was resampled to the $800-\mathrm{m}$ resolution of the established GIS database. For each texture class a percent of clay and a percent of sand were assigned based on soil texture samples and published data (Jackson et al., 1999). These two data layers were input for further model calculations.

Soil temperature data were needed for computing the emissivity of soils. Data collected at the 112 Oklahoma Mesonet stations, at $10 \mathrm{~cm}$ under sod for each day, were interpolated into 800-m grid. Temperature information was stored as separate data layers for each day of the observation period.

Also, cumulative rainfall for the 24 hours prior to the ESTAR observation were obtained from the Oklahoma Mesonet stations for each day of the experiment. Interpolation to $800-\mathrm{m}$ grid resulted in a spatial product. These data layers were important while soil moisture distribution was analyzed and assessed.

\section{Ground truth data}

On each day of the experiment, soil samples were collected from the top layer of the soils at sites in the Central Facility, El Reno and Little Washita areas (see Fig. 1). In each area there were 10 to 14 smaller test sites (usually of the size 800 by $800-\mathrm{m}$ ) of uniform land cover, texture and topography (Jackson et al., 1999). Samples were taken from 14 points (of the depth $0-5 \mathrm{~cm}$ ) from the each of the test sites at the time of the aircraft overflight. Volumetric soil moisture was determined and averaged within the test sites. These data were later used for model validation.

\section{Model calculations and validation}

All needed GIS database layers were assembled and merged for soil moisture algorithm calculations. Using these spatial data as the input to the model, computation was performed for each day of the experiment. The retrieval algorithm, as described in Jackson (1993), was implemented inside the GIS.

Preliminary results were compared with the ground truth data (see Fig. 2). The comparison revealed that the model parameters needed adjustment, especially those associated with land cover types. Corrections for the input values of the vegetation parameter and vegetation water content were done, especially within the areas covered by dense native grasses (Jackson et al., 1999).

1 STATSGO stands for the State Soil Geographic Data Base for the conterminous United States developed by USDA Natural Resources Conservation Service. 


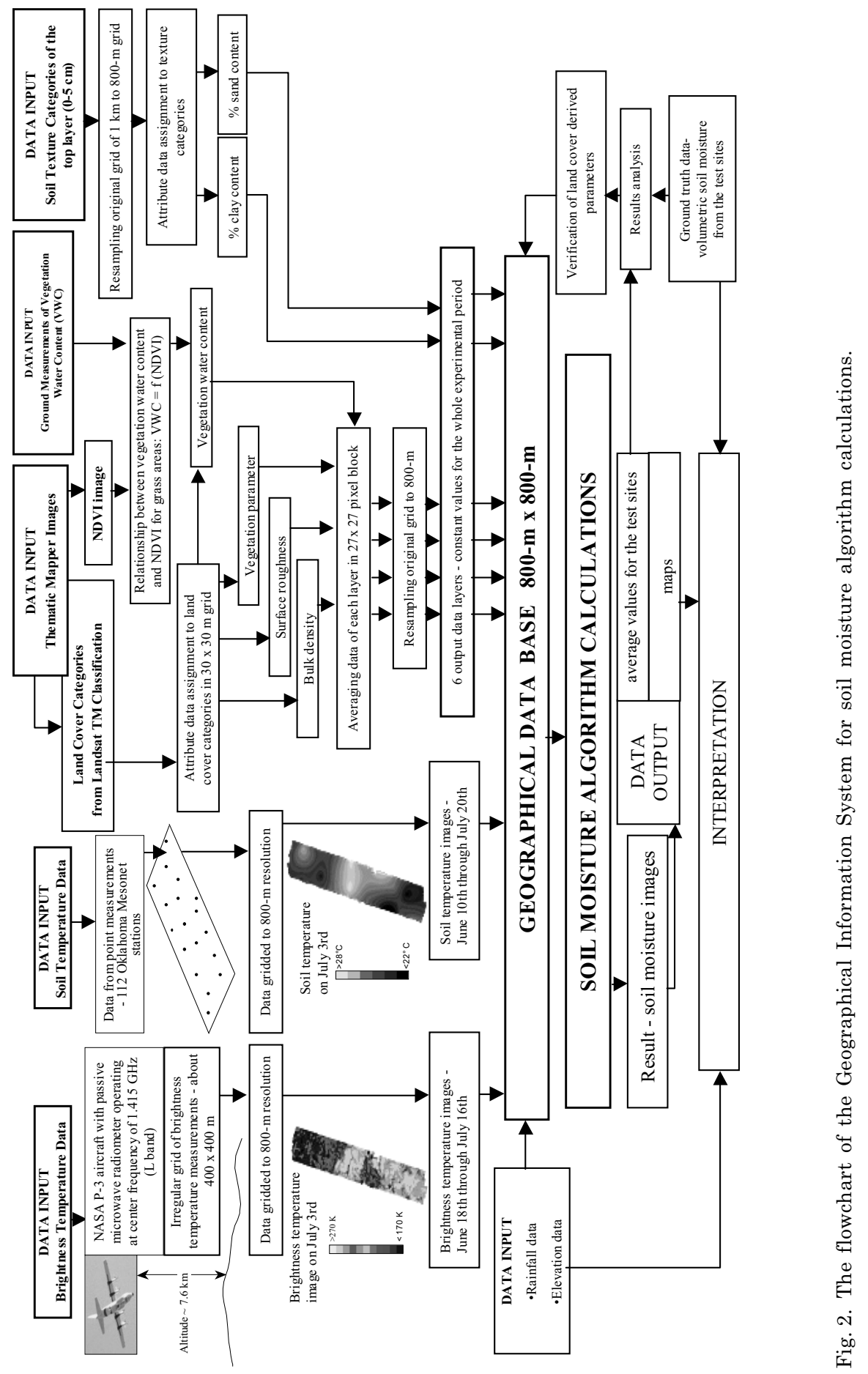


Finally, after the model validation, soil moisture images for 16 days during the experiment were produced (as shown in Fig. 3).

\section{RESULTS AND DISCUSSION}

The resulting set of images provides information on the spatial and temporal dynamics of volumetric soil moisture in the surface layer. The comparison of results obtained by model prediction and ground measurement indicated an error level on the order of 3\% (Jackson et al., 1999). In case of El Reno area, which was covered by dense native grass, the predicted soil moisture was found to be lower then the ground measurements. The opposite situation was found for sites in Central Facility area, which consisted mostly of winter wheat.

The soil moisture over the whole region varies because of wetting by rainfall events and periods of drying. The sequences of images show the drying periods for $18^{\text {th }}-20^{\text {th }}$ June, $1^{\text {st }}-3^{\text {rd }}$ July and $12^{\text {th }}-14^{\text {th }}$ July (see Fig. 3 ). The average soil moisture for each day of the drying periods is decreasing, as shown on Fig. 4 (note that the mean VSM presented here was computed for the common area for all the 15 days, excluding $11^{\text {th }}$ July). The northern part of the region was usually wetter compared to the central and southern parts as a result of larger and more frequent rain.

One of the advantages of an integrated GIS system as used here is the ease with which the final result - soil moisture maps - can be compared to soil texture, rainfall distribution and other environmental features. The results of the experiment were used in semivariogram and multiscaling analysis (Oldak et al., 2001; Oldak et al., in press). Also, the relationship between elevation and volumetric soil moisture was analyzed for this study, as topography is commonly viewed as a significant factor in soil moisture distribution in landscapes (i.e. Falkenmark and Mikulski, 1994). A simple linear regression did not show any relationship between elevation and volumetric soil moisture. However, the analysis with cross-correlograms as a measure of spatial variability gave some interpretable results (data not shown due to the limited length of the paper). Generally, the weak negative correlation can be noticed up to $100-\mathrm{km}$ lag distance on each considered drying period. The strength of relation depends on the intensity of rainfall event. After heavy rain, like on $30^{\text {th }}$ June, the negative correlation between elevation and soil moisture contents appears to be the strongest comparing to two other drying events. As expected, the weakest relation occurs when the amount of the volumetric soil moisture is the lowest.

Not significant correlation between elevation and soil moisture content is understandable after considering the source of soil moisture data. The ESTAR measurement of soil moisture comes from the top layer $(0-5 \mathrm{~cm})$, which is controlled by the high evaporation in Oklahoma's semi-arid climate. The evaporation is responsible for drying pattern and appears before runoff can take place. This is especially true after small rainfall events. 


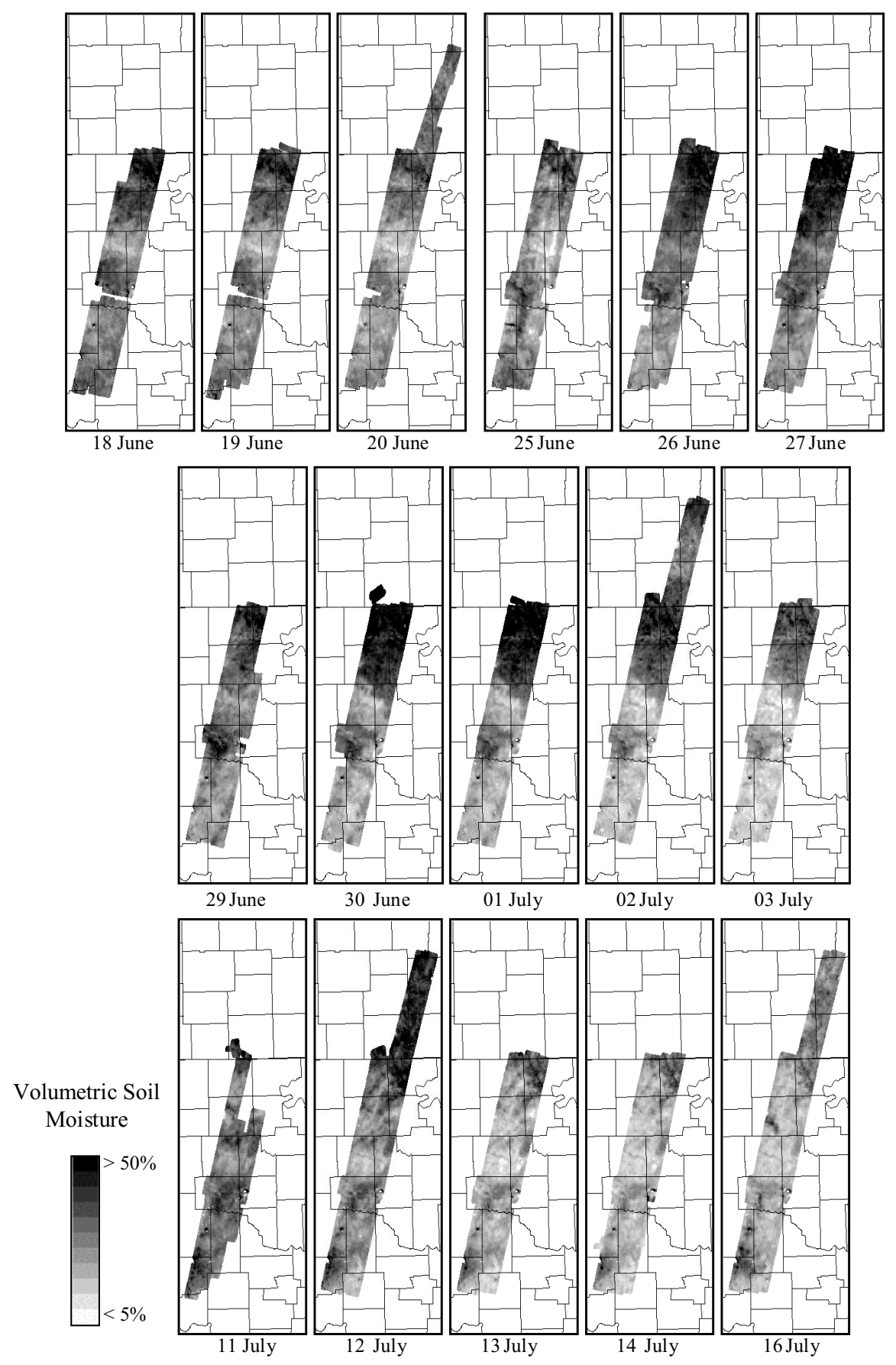

Fig. 3. Soil moisture images. 


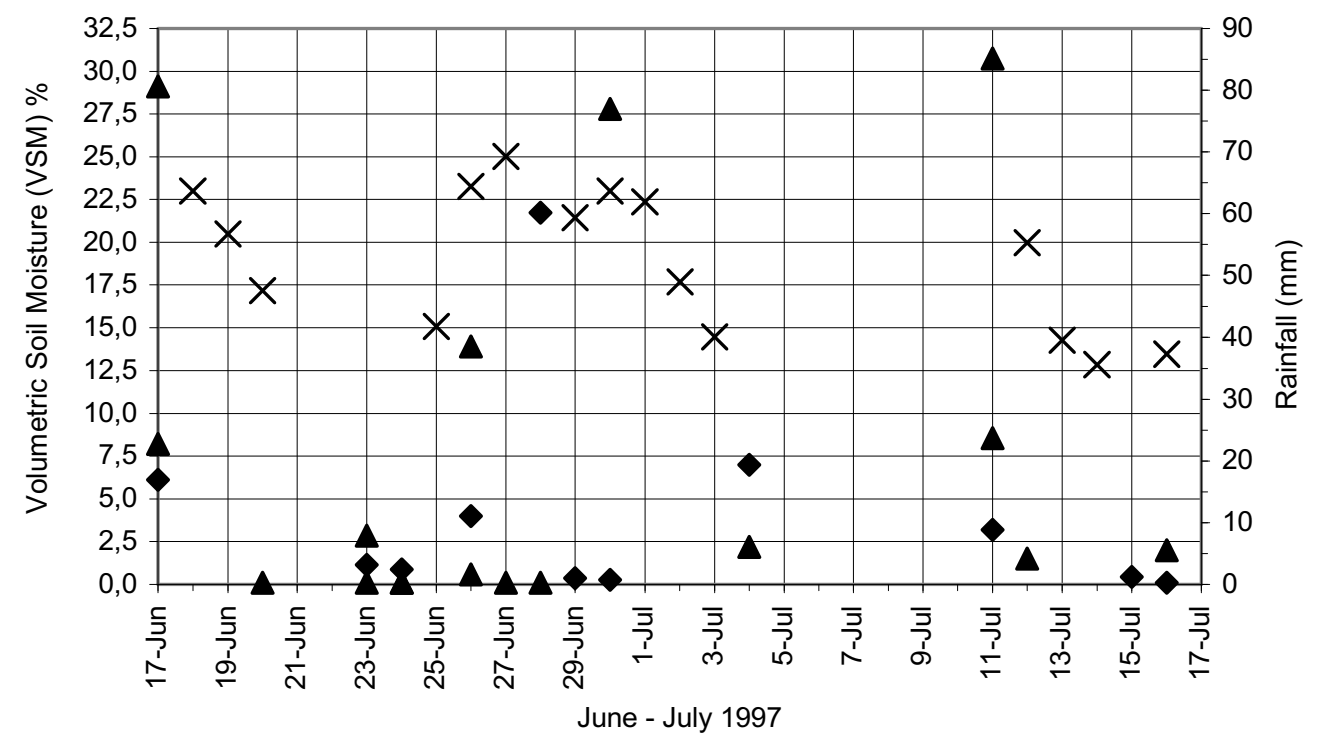

$X$ mean VSM $\Delta$ CF rainfall $\bullet$ ER rainfall $\Delta \mathrm{LW}$ rainfall

Fig. 4. Rainfall events recorded at meteorological stations close to the test sites - Central Facility (CF), EL Reno (ER) and Little Washita (LW) and mean volumetric soil moisture (VSM) in $\%$ for the each of the 16 days of observation.

\section{CONCLUSIONS}

Microwave remote sensing offers a quick and reliable way of mapping an important feature of landscapes - soil moisture. Passive microwave remote sensing is currently the most reliable approach. This and previous experiments (Jackson et al., 1999; 1995) proved the reliability of using passive microwave instrument in soil moisture mapping.

Knowledge of the soil moisture spatial and temporal distribution is useful in land management and landscape ecology investigations involving the interactions between environmental components. The temporal series of soil moisture maps over large areas enable the analysis of its distribution in relation to different landscape features. Understanding factors responsible for soil moisture diversification is very helpful in the land use assessment and its management. Additionally, they offer help in predicting and assessing flow of the matter and energy between land surface and atmosphere. Passive microwave soil moisture detection demonstrates a sufficient tool in increasing remote sensing research in landscape ecology. 


\section{REFERENCES}

Doraiswamy P., Stern A.J., Cook P.W., 1998, Classification techniques for mapping biophysical parameters in the U.S. Southern Great Plains, Proceedings of the International Geosience and Remote Sensing Symposium, IEEE Catalog No. 007803-4403, Vol. II, $862-865$.

Du Y., Ulaby F.T. and Dobson M.C., 2000. Sensitivity to soil moisture by active and passive microwave sensors, IEEE Transactions on Geoscience and Remote Sensing, 38 (1), $105-114$.

Falkenmark M., Mikulski Z., 1994, The key role of water in the landscape system, GeoJournal, 33.4, 355-363.

Frohn R.C., 1998, Remote sensing for landscape ecology, Lewis Publishers. Boca Raton.

Gray F., Gallow y H.M., 1969, Soils of Oklahoma, Misc. Publication. Oklahoma Agricultural Experiment Station, Oklahoma State University, Stillwater. OK. 65 p.

Jacks on T.J., 1993, Measuring surface soil moisture using passive microwave remote sensing, Hydrological Processes, 7, 139-152.

Jackson T.J., Le Vine D.M., Hsu A.Y., Oldak A., Swift C.T., Isham J., Haken M., 1999, Soil moisture mapping at regional scales using microwave radiometry: the Southern Great Plains Hydrology Experiment, IEEE Transactions on Geoscience and Remote Sensing, 37 (5), 2136-2151.

Jackson T.J., Le Vine D.M., Swift C.T., Schmugge T.J., Schiebe F.R., 1995, Large area mapping of soil moisture using the ESTAR passive microwave radiometer in Washita'92, Remote Sensing of Environment, 53, 27-37.

J a cks on T.J., Schmugge T.J., 1991, Vegetation effects on the microwave emission of soils, Remote Sensing of Environment, 36, 203-212.

Jackson T.J., Schmugge J., Engman E.T., 1996, Remote sensing application to hydrology: soil moisture, Hydrological Sciences, 41 (4), 517-530.

Johnst on C.A., 1998, Geographic Information Systems in ecology, Blackwell Science Ltd. UK.

Miller D.A., 1997, Planning in-situ soil moisture observations for climate and hydrology studies, 13th Conference on Hydrology, American Meteorological Society, Long Beach. California.

Oldak A., Pachepsky Y., Jackson T.J., Rawls W.J., Statistical properties of soil moisture images revisited, Journal of Hydrology (in press).

Oldak A., Jackson T.J., Pachepsky Y., 2001, Soil moisture mapping with passive microwave imagery and geostatistical analysis, Remote Sensing and Hydrology 2000, IAHS Publ., no. 267, 379-383.

Oldak A., Jackson T.J., 1999, Using GIS in passive soil moisture mapping on a regional scale, Proceedings of the International Geoscience and Remote Sensing Symposium, IEEE Catalog No. 99CH36293, Vol. II, 1118-1120.

Quattrochi D.A., Pelletier R.E., 1991, Remote sensing for analysis of landscapes: An introduction, [in:] Quantitative Methods in Landscape Ecology, 51-76. Edited by Turner, M.G. and Gardner, R.H. Springer-Verlag. New York.

Wu S.T., 1984, Analysis of synthetic aperture radar data acquired over a variety of land covers, IEEE Transactions on Geoscience and Remote Sensing, GE-22, 550-557. 